\title{
Recovery of function after brain damage: Support for the compensation theory of the behavioral deficit
}

\author{
N. DAVIS LeVERE and T. E. LeVERE \\ North Carolina State University, Raleigh, North Carolina
}

\begin{abstract}
It has recently been suggested that the behavioral deficit following brain injury is not exclusively the result of the neurological loss of the system components that had subserved the behavior in the normal animal. Rather, the behavioral deficit is viewed as the result of an underutilization of what is spared of the affected neural system. According to this view, an overt behavioral deficit occurs because the residual spared functioning of the damaged system is suppressed, masked, or dominated by the functioning of the neural systems that remain intact. The present series of studies supports this interpretation by demonstrating that prior to recovering a visual behavior, a visual decorticate rat, in contrast to a normal rat, will ignore visual cues and respond to nonvisual cues when attempting to avoid and/or escape mild footshock.
\end{abstract}

Traditionally, the behavioral dysfunctions that follow brain injury have been exclusively attributed to neurological losses. Accordingly, because of these assumed neurological losses, recovery of function has necessarily been viewed as a process of neural reorganization, vicariation, and relearning. Even though this general thesis never has enjoyed direct empirical validation, its simplicity and intuitive reasonableness nonetheless have served to establish it as a basic heuristic underlying much of our research concerning the effects of brain injury and the process of recovery of function. However, beyond the general consensus that the initial effects of brain injury are more severe than the later effects, only a very few, highly qualified relationships have evolved from this traditional perspective on recovery from brain damage (LeVere, 1980; LeVere, Davis, \& Gonder, 1979).

One critical reason for this lack of progress may be that the definition of the problem is itself fundamentally incorrect. This possibility was outlined a decade ago by Meyer (1972), who interpreted some recovery of function data as indicating that the recovery process may be more akin to remembering what to do as opposed to relearning what to do. This proposition was interesting because, as suggested, if what is recovered is what is remembered, then the recovered

This research was supported by Research Grant NS-12459 from the National Institute of Neurological and Communicative Disorders and Stroke to T. E. LeVere. The authors wish to express appreciation to the anonymous "long reviewer" for his/her invaluable comments. Requests for reprints should be directed to N. Davis LeVere, Neuropsychology Laboratory, Department of Psychology, North Carolina State University, Raleigh, North Carolina 27650. behaviors must have been spared by the neural insult even though there is an initial behavioral deficit. In other words, it is possible that the majority of research and theory concerning recovery of function has been less than satisfying simply because it has been an attempt to investigate and explain the reversal of something that has not occurred: namely, the loss of the capacity to perform certain behaviors.

However, to suggest that the recovery of some specific behavior rests on a substantial sparing of the morphological and functional components of that behavior would seem to involve a logical problem: If the morphological and functional components of a particular behavior are spared, then recovery of function should not be at issue, since, by definition, there should not be a behavioral deficit (Laurence \& Stein, 1978). At face value, this reasoning is compelling and seems to identify a serious flaw in the suggestion that recovery of function depends upon sparing. Yet, it is important to realize that this argument presupposes the validity of a questionable assumption. This assumption is that, following brain injury, the affected subject is able to, and will, effectively utilize all neural mechanisms that are spared by the brain injury. However, as previously pointed out (LeVere, 1975), there is even less empirical evidence for this supposition than there is for the suggestion that neural reorganization is responsible for recovery of function.

In fact, there are considerable data that directly contradict the suggestion that the brain-injured individual utilizes all spared neural mechanisms (see LeVere, 1980, for review). For example, Ommaya and Bossom (see summary by Guth, 1974) report that monkeys sustaining unilateral spinal deafferentation will never utilize their ipsilateral limbs in any useful 
fashion unless their contralateral limbs are physically restrained. A similar effect follows unilateral motor cortex lesions in monkeys (Lashley, 1924). Or, consider that the contralateral hemianopia produced by unilateral visual neocortex ablation in rats and cats is immediately reversed by destroying the superior colliculus opposite to the initial visual insult (Cooper, Bland, Gillespie, \& Whitaker, 1970; Kirvel, Greenfield, \& Meyer, 1974; Sprague, 1966). Moreover, this sort of result is not restricted to unilateral neural damage but also occurs following symmetrical bilateral brain injuries. For example, there is a sudden reinstatement of visual placing when cats with extensive neocortical ablations are administered the drug amphetamine (Meyer, Horel, \& Meyer, 1963). Likewise, amphetamine facilitates the postoperative recovery of a preoperatively learned brightness discrimination (Braun, Meyer, \& Meyer, 1966). These are, of course, the more salient examples of the brain-injured subject's not utilizing all spared and potentially useful neural capacities. However, to our knowledge, there is no evidence that directly challenges this assertion.

On the basis of these kinds of data, we have recently proposed that in certain instances, perhaps many instances, the postlesion behavioral deficit may reflect inappropriate compensatory behaviors that develop because of an underutilization of the neural system affected by the brain lesion (LeVere, 1980). Basically, two assumptions underlie this proposal. First, we suggest that all individuals, normal and brain-injured, are optimizers. By this we mean that each individual will attempt to behave by utilizing the most effective sensory, cognitive, and/or motor capacities at its disposal. Second, we suggest that brain injury will always produce some degradation of some sensory, cognitive, and/or motor capacities. From this perspective, an individual's initial general reaction to brain injury may be characterized as underutilization of the injured neural system and compensation via behaviors mediated by other, relatively undamaged, neural systems. While this compensatory responding may be successful in certain situations (for example, the "tricks" described by Goldberger, 1972; Sperry, 1947), it will be unsuccessful when the situation requires a specific behavior that is critically dependent upon the damaged but unutilized neural system that precipitated the compensation in the first place. We suggest that it is this occurrence of unsuccessful compensatory responses that is typically identified as the postoperative behavioral deficit.

The importance of the above concept is that a specific behavioral deficit is not exclusively determined by a specific neurological loss. To be sure, the brain injury and the neurological loss are the precipitating conditions. However, it does not necessarily follow from this that all specific behavioral deficits suffered by the brain-injured subject occur because the neural mechanisms responsible for the behaviors are lost. Rather, the critical neural mechanisms may be spared but simply not utilized.

The purpose of the present experiments was to directly test the hypothesis that compensation may be one of the major determinants of a postoperative behavioral deficit. To accomplish this we used the shock-motivated two-choice brightness discrimination procedure that we previously had used to evaluate recovery of function following visual decortication in rats (see LeVere \& Morlock, 1973). However, during postoperative recovery training in the present experiments, the brightness cues were compounded with supplemental nonvisual discriminative cues. Our prediction was that, if underutilization and compensation suppress the expression of what is spared of an injured neural system, then the visual decorticate rat should preferentially attempt to avoid/escape shock on the basis of these supplemental nonvisual cues and ignore the brightness cues.

\section{EXPERIMENT 1}

To begin this investigation, we first tested a number of different visual/nonvisual compound-cue discrimination problems in a series of transfer-oftraining experiments with normal animals. Our goal was to define a visual/nonvisual compound-cue discrimination with which, after learning the discrimination, normal animals would show good transfer to either the visual or nonvisual component of the compound. Note that, while equal salience was not the issue, it was critical to show that normal rats would respond to the nonvisual component during compound-cue training. This was important because, if the normal rat did not utilize the nonvisual component when learning the compound visual/nonvisual discrimination, then we would have no firm reason to believe that the lesioned rat would do so if and when it compensated for a visual neocortical injury. The final experiment in this series of transfer-of-training experiments is described below.

\section{Method}

Subjects. Twenty-four normal male hooded rats between 90 and 120 days of age were used. They were born in our laboratory colony, reared and maintained on a reversed 10:14-h day:night cycle, and housed throughout the experiment in individual cages with free access to food and water.

Apparatus. The apparatus was a modified version of our Yerkes two-choice brightness discrimination box (see LeVere \& Morlock, 1973). It consisted of a start compartment separated from a choice compartment by a guillotine door. At the end of the choice compartment were two goal areas. The animal could enter the correct goal area by knocking down the translucent door at the entrance. The two goal areas were separated by a thin divider panel that extended $15 \mathrm{~cm}$ into the choice compartment. The floors of the start compartment and the choice compartment were constructed of brass rods to allow delivery of pulsating footshock $(.5 \mathrm{sec}$ on, $.5 \mathrm{sec}$ off). The shock current was individually adjusted for each 
animal and set to a level between .3 and $.8 \mathrm{~mA}$ that was just sufficient to insure consistent responding.

The brightness-discrimination cues were produced by transilluminating the goal-area doors with flood lamps located in tunnels extending back from the clear plastic rear wall of each goal area. The voltage to these lamps was adjusted to transilluminate the goal-area doors with a brightness of $64 \mathrm{fL}$ as measured by a Tektronix J16 photometer ( $\mathrm{J} 6503$ probe) from rat eye level in the choice compartment. The 64-fL brightness served as the brighter discriminative cue, and the dimmer discriminative cue was produced by placing an aluminum panel with a small aperture in front of the other flood lamp to restrict its light output to $1 \mathrm{fL}$. Whenever the rat completed a correct choice response by pushing down the correct goal-area door, a microswitch immediately extinguished both flood lamps.

The nonvisual cues were similar to the step-through haptic cues described by Glendenning, Howard, and Meyer (1971). These cues, constructed of the same translucent material used for the goalarea doors, extended from floor to ceiling and from each sidewall to the center divider panel. One of the haptic cues had an inverted triangular opening extending from the two upper corners to the center of the panel over which the rat had to crawl. The other haptic cue had an upright triangular opening extending from the two bottom corners to the center of the panel under which the rat had to crawl. However, by themselves the step-through haptic cues contributed less than we desired to the compound-cue discrimination as measured by subsequent transfer training. Accordingly, the bottom-to-center upright-triangle haptic cue was always thoroughly washed before it was used, whereas the top-to-center invertedtriangle haptic cue was odorized by placing it under a cage containing six to eight juvenile rats for $12 \mathrm{~h}$ before it was used. We, of course, realize that there are obviously more systematic and controllable procedures for creating haptic-odor discriminanda; but, at the time, we felt that an odor that was intimately familiar to the subjects would be preferable.

During training with the compound cues, the haptic cues and the brightness cues were simultaneously available, with the haptic-cue components located at the forward end of the center divider panel, that is, $15 \mathrm{~cm}$ in front of the translucent goal-area doors that provided the brightness cue components of the compound.

Procedure. The procedure for this experiment was a classic transfer of training routine. Initially, two groups of rats were trained with the visual/nonvisual compound discriminative cues. In both of these groups, the visual cues were relevant to the discrimination task, with the dimmer visual cue always associated with the location of the unlocked door of the correct goal area. The haptic-component cues, on the other hand, were relevant for one of these two groups and irrelevant for the other group. That is, one group $(n=16)$ was trained with the haptic-component cues redundant to the brightness component cues and thus relevant to the discrimination task (the brightness/haptic-relevant, or $\mathrm{B} / \mathrm{Hr}$, group). In this group, the dimmer visual cue and the under-thecage top-to-center inverted triangular haptic cue were always paired together and always signaled the location of the correct goal area. In the other group $(n=8)$, the left-right position of the two haptic component cues was random with respect to the relevant brightness component cues and thus irrelevant to the discrimination task (the brightness/haptic-irrelevant, or B/Hi, group).

For each group, training was in accord with our usual procedures. First, a rat was placed in the start compartment, and the guillotine door was raised. The rat was then allowed $10 \mathrm{sec}$ to exit the start compartment before pulsating footshock was initiated. Once in the choice compartment, the rat was allowed an additional 10 -sec shock-free interval to complete its choice by crawling under or jumping over one of the haptic cues and attempting to push down the entrance to the goal area. If the rat did not complete its choice in $10 \mathrm{sec}$, then the pulsating footshock was reinstated until it did so. If the rat made an incorrect choice by pushing on the locked brighter goal-area door, then the pulsating shock became steady until the rat corrected its error. This training routine progressed at a rate of 10 trials/day, with the left-right position of the correct goal area varying in a pseudorandom fashion requiring that each position be correct five times during each training session and that no position be correct more than three times in succession. Daily training continued until an animal reached a criterion of nine first-choice correct responses within 1 day's training.

On the day following criterion performance with the compound discriminative cues, transfer of training began. Half of the animals in the B/Hr group were trained with only the brightness- (B) component cues, while the remaining animals of this group were trained with only the haptic- $(\mathrm{Hr})$ component cues. For the animals trained with only the haptic component, both goal-area doors were transilluminated to a brightness of $8 \mathrm{fL}$, that is, a brightness that was intermediate between the brightness cues of the $\mathrm{B} / \mathrm{Hr}$ compound.

All of the animals of the $\mathrm{B} / \mathrm{Hi}$ group were given transfer training with only the brightness (B) component cues of the $\mathrm{B} / \mathrm{Hi}$ compound.

Other than these changes in discriminative cues, transfer training followed the same routine as the initial compound-cue training and continued to the same criterion.

\section{Results and Discussion}

The results of this experiment are summarized in Table 1, which gives the mean errors to criterion during the initial compound-cue training and during the subsequent transfer training. Criterion performance on the initial $\mathrm{B} / \mathrm{Hr}$ compound-cue problem was reached with an average of 6.5 errors by those animals that transferred to the B component and with an average of 8.6 errors by those animals that transferred to the $\mathrm{Hr}$ component. Since the difference between these error scores was not significant $[t(14)=$ 1.273], the $\mathrm{B} / \mathrm{Hr}$ data were pooled for analysis.

During the compound-cue training, the animals trained with the $\mathrm{B} / \mathrm{Hr}$ compound cues committed an average of 7.6 errors before reaching criterion, while the animals trained with the $\mathrm{B} / \mathrm{Hi}$ compound cues averaged 16.0 errors. This 8.4 -error difference is significant $[\mathrm{t}(22)=3.231, \mathrm{p}<.01]$. Notwithstanding this difference, however, there were no differences among any of the transfer-training groups $(F<1)$. Moreover, each of these groups showed significant positive transfer from their respective compound-cue

\section{Table 1}

\begin{tabular}{ccccc}
\hline \multicolumn{2}{c}{ Compound-Cue } & Training & & \multicolumn{2}{c}{ Transfer Training } \\
\cline { 4 - 5 } Cue & Errors & & Cue & Errors \\
\hline B/Hr & 7.6 & $\mathrm{~B}$ & 2.0 \\
$\mathrm{~B} / \mathrm{Hi}$ & 16.0 & $\mathrm{Hr}$ & 1.5 \\
\hline
\end{tabular}

Note-Results are for the normal group. $B=$ brightness cues (always relevant, dark correct); $\mathrm{Hr}=$ haptic cues when relevant (and redundant to brightness cues in compound cues); $\mathrm{Hi}=$ haptic cues when irrelevant (and random to brightness cues in compound cues); $\mathrm{B} / \mathrm{Hr}=$ compound cues composed of brightness components and relevant haptic components; $B / H i=$ compound cues composed of brightness components and irrelevant haptic components. 
problems, that is, $\mathrm{B} / \mathrm{Hr}$ transferring to $\mathrm{B}[\mathrm{t}(7)=3.589$, $\mathrm{p}<.01], \mathrm{B} / \mathrm{Hr}$ transferring to $\mathrm{Hr}[\mathrm{t}(7)=4.230, \mathrm{p}<$ $.01]$, and $B / H i$ transferring to $B[t(7)=4.198, p<$ $.01]$.

On the basis of these data we believed that we had defined a nonvisual discriminative cue that would influence a normal rat's performance about as much as the visual cues we typically use. Our question now was whether this result would also hold for visual decorticate rats.

\section{EXPERIMENT 2}

The compensatory explanation of a postoperative behavioral deficit maintains that, following brain injury, a subject will attempt to compensate for the injury by preferentially utilizing those neural systems not directly affected by the lesion. The result of this shift in behavioral control is that, independently of what may be spared, the lesioned neural system will have little influence on overt behavior. Consequently, the brain-injured subject will experience considerable difficulty in expressing any behavior that is dependent upon the lesioned neural system.

If this explanation of the postoperative behavioral deficit is valid, then the effects of compensation should be clearly evident in the behavior of visual decorticate rats in the compound-cue transfer-oftraining paradigm described in Experiment 1. For example, during initial learning with compound cues, the visual decorticate rat should perform very well when trained with the $\mathrm{B} / \mathrm{Hr}$ compound cues but should perform very poorly when trained with the $\mathrm{B} / \mathrm{Hi}$ compound cues. The reason for this prediction is that, in both cases, the compensatory behavior of the visual decorticate rat should direct the animal's responses to the haptic components of the compound cues, which in the $\mathrm{B} / \mathrm{Hr}$ case are relevant to the task but in the $\mathrm{B} / \mathrm{Hi}$ case are irrelevant to the task.

During the initial compound-cue phase of transfer training, there also should be detectable effects of any compensation. For example, if the lesioned rat compensated when learning the $\mathrm{B} / \mathrm{Hr}$ compound-cue problem, then the visual decorticate rat, like the normal rat, should show very good transfer to the $\mathrm{Hr}$ component cue but, unlike the normal rat, should show very poor transfer to the B-component cue. The reason for this prediction is that, if the lesioned rat compensates during its compound-cue training, then it should preferentially respond to the haptic component and learn very little about the relevance of the brightness component. Accordingly, during the transfer training, the visual decorticate animal transferring to the $\mathrm{Hr}$-component cues is doing exactly what it learned from its experience with the $\mathrm{B} / \mathrm{Hr}$ compound cues. On the other hand, the lesioned animal transferring to the B-component cues is not doing what it learned when it mastered the $\mathrm{B} / \mathrm{Hr}$ compound-cue discrimination and must relearn the problem. This, however, should not be the case for those animals initially trained with the $\mathrm{B} / \mathrm{Hi}$ compound cues. In this case, the visual decorticate rat should show good transfer to the B-component cues because the only way the $\mathrm{B} / \mathrm{Hi}$ problem could have been solved was for the lesioned animal to inhibit its compensatory selection of the haptic-component cues and respond to the B-component cues.

The purpose of Experiment 2 was to test these predictions of the compensation theory of a postoperative behavioral deficit.

\section{Method}

Subjects. The subjects for this experiment were 29 male hooded rats between the ages of 90 and 120 days. The animals were from our colony and were maintained as described in Experiment 1.

Apparatus. The apparatus, visual cues, and haptic cues were identical to those used in Experiment 1.

Procedure. The experiment was an exact replication of Experiment 1 except that the animals were subjected to posterior visual decortication 2 weeks prior to beginning the experiment.

Surgery. The visual decortications were performed under clean surgical conditions, and sodium pentobarbital was used as the anesthetic agent. The lesions were quite large and were intended to include all neocortex posterior to bregma that receives visual thalamic projections as described by Hughes (1977). Following surgery, each animal was given a prophylactic injection of a broadband antibiotic $(9,000$ units of penicillin $G$ benzathine and penicillin $\mathrm{G}$ procaine in aqueous suspension, im).

Histology. Histology followed our standard routines. That is, each animal was anesthetized and perfused via the intracardial route, and its brain was removed. The extent of the neocortical lesion was then drawn on surface diagrams with the aid of a dissecting microscope. The brains were then sunk in a solution of sucrose and formalin and sectioned on a freezing microtome at a thickness of $50 \mu$. Every fourth section was saved and stained with cresyl violet.

\section{Results and Discussion}

Histology. Figure 1 shows the surface diagrams of the brains of the animals sustaining the smallest and largest lesions. The mean cortical destruction found in the animals of the $\mathrm{B} / \mathrm{Hr}$ group that transferred to the B-component cues was $41.8 \%$, and the mean destruction of the $\mathrm{B} / \mathrm{Hr}$ animals that transferred to the Hr-component cues was $41.7 \%$. The mean cortical destruction of the animals in the $\mathrm{B} / \mathrm{Hi}$ group was $42.5 \%$. These differences were not significant ( $F<1)$.

Microscopic analysis of the cresyl-stained material showed complete destruction of all six neocortical layers without bilateral invasion of any subcortical area. In all subjects, there was complete degeneration within the dorsal lateral geniculate nucleus.

Behavior. The behavioral results of Experiment 2 are presented in Table 2, which duplicates Table 1 and adds the lesion-first data of the present experiment. During their initial training with the $\mathrm{B} / \mathrm{Hr}$ compound cues, the rats that transferred to the 

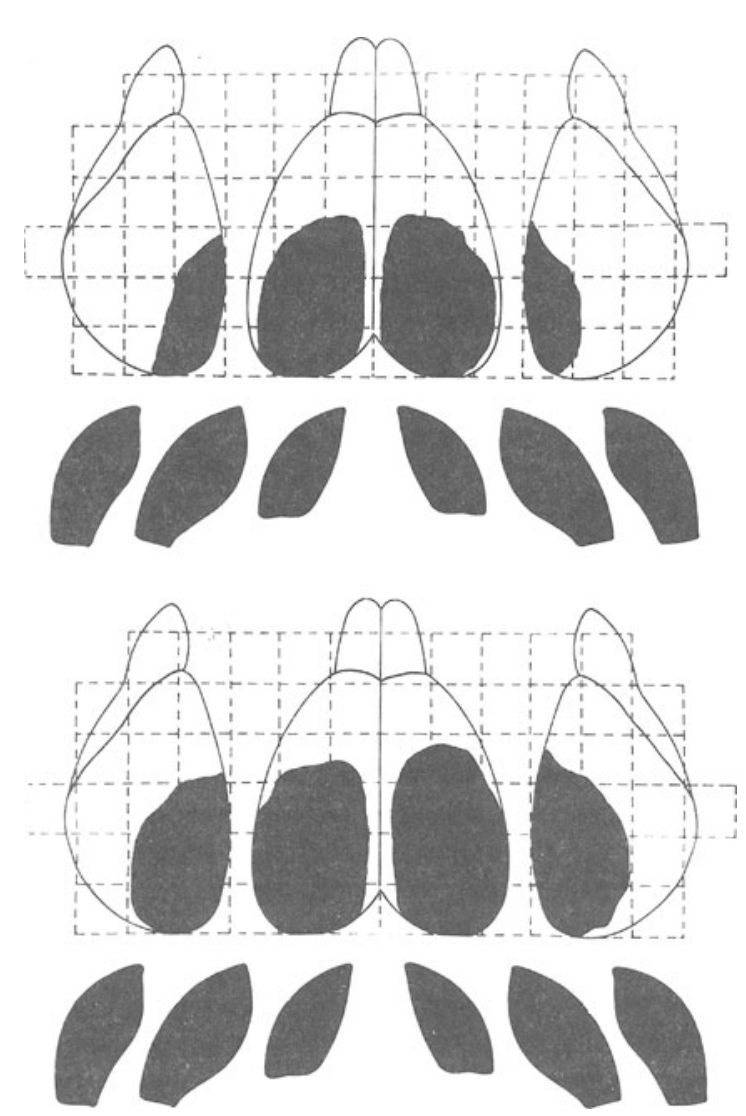

Figure 1. Diagrams of the surface destruction and dorsal lateral geniculate degeneration (blackened areas) for the animal sustaining the smallest lesion (top of figure) and the animal sustaining the largest lesion (bottom of figure) in Experiment 2.

B component averaged 4.0 errors to criterion and the rats that transferred to the $\mathrm{Hr}$ component averaged 3.6 errors. Since the difference between these scores was not significant $[t(18)=.327]$, the data from the $\mathrm{B} / \mathrm{Hr}$-trained rats were pooled for analysis.

Consider first the performance of the visual decorticate rats initially trained with either the $\mathrm{B} / \mathrm{Hr}$ or the $\mathrm{B} / \mathrm{Hi}$ compound cues. Like normal animals, the operated rats were significantly impaired by the presence of irrelevant haptic cues $[\mathrm{t}(27)=10.115$, $\mathrm{p}<.001$ ]. In the present case, however, the impairment was much more severe. Whereas the normal rats made only about twice as many errors on the $\mathrm{B} / \mathrm{Hi}$ problem as they did on the $\mathrm{B} / \mathrm{Hr}$ problem, the visual decorticate rats committed over seven times as many errors on the $\mathrm{B} / \mathrm{Hi}$ problem as on the $\mathrm{B} / \mathrm{Hr}$ problem. Moreover, it is critical to note what contributes to this differential. On the one hand, the visual decorticate rats made significantly more errors on the $\mathrm{B} / \mathrm{Hi}$ problem than did their normal counterparts $[\mathrm{t}(15)=2.527, \mathrm{p}<.05]$, as predicted by compensation theory. However, since this increase in errors might simply have been a general effect of neocortical injury, it is of considerably more interest that the visual decorticate rats made significantly fewer errors on the $\mathrm{B} / \mathrm{Hr}$ problem than did the normal rats $[t(34)=3.270, p<.01]$ : one of the very few instances that we know of in which a visual neocortical lesion was of any benefit whatsoever! Yet, the result affirmed the somewhat bizarre prediction of the compensation theory that brain injury would facilitate the performance of behaviors not directly under the control of the lesioned neural systems.

Turning to the transfer training performance, the results also reflected important lesion-induced compensatory behavioral differences between the visual decorticate rats and their normal counterparts. During transfer training, the normal animals showed positive, and about equal, transfer to each of the relevant components of a previously learned compound-cue discrimination. This was not, however, the case with the visual decorticate rats, for which there were substantial differences in performance during transfer training $[F(2,26)=16.875$, $\mathrm{p}<.01$ ]. For example, the visual decorticate rats, like the normal rats, showed significant positive transfer to the $\mathrm{Hr}$ component after initial training with the $\mathrm{B} / \mathrm{Hr}$ compound cues $[\mathrm{t}(9)=2.521, \mathrm{p}<.05]$. It is interesting, though, that the visual decorticate rats initially trained on the $\mathrm{B} / \mathrm{Hr}$ compound showed, unlike the normal rats, significant negative transfer to the $B$ component $[t(9)=3.237, p<.02]$. However, this is exactly what was predicted by the compensation theory, since the theory suggested that the visual decorticate rats would compensate during the $\mathrm{B} / \mathrm{Hr}$ training and would respond only to the $\mathrm{Hr}$ component. On the other hand, it is important to note that the visual decorticate rats showed positive transfer to the B-component cue if they were initially trained

Table 2

\begin{tabular}{cccc}
\hline \multicolumn{2}{c}{ Compound-Cue Training } & \multicolumn{2}{c}{ Transfer Training } \\
\cline { 2 - 4 } \cline { 3 - 4 } Cue & Errors & Cue & Errors \\
\hline \multicolumn{4}{c}{ Normal Group } \\
B/Hr & 7.6 & $\mathrm{~B}$ & 2.0 \\
B/Hi & 16.0 & $\mathrm{Hr}$ & 1.5 \\
& Lesion-First Group & 1.6 \\
B/Hr & 3.8 & $\mathrm{~B}$ & \\
B/Hi & 28.1 & $\mathrm{Hr}$ & 1.1 \\
& & $\mathrm{~B}$ & 3.9 \\
\hline
\end{tabular}

Note $-B=$ brightness cues (always relevant, dark correct); $\mathrm{Hr}=$ haptic cues when relevant (and redundant to brightness cues in compound cues); $\mathrm{Hi}=$ haptic cues when irrelevant (and random to brightness cues in compound cues); $\mathrm{B} / \mathrm{Hr}=$ compound cues composed of brightness components and relevant haptic components; $B / H i=$ compound cues composed of brightness components and irrelevant haptic components. Animals in the lesion-first group sustained visual decortication before compound-cue training. 
with the $\mathrm{B} / \mathrm{Hi}$ compound $[\mathrm{t}(8)=8.393, \mathrm{p}<.001]$. But, this too was predictable, since any compensation to the haptic-component cues during the $\mathrm{B} / \mathrm{Hi}$ training would be ineffectual and the animals would ultimately have to respond to the brightness-component cues to solve the problem.

Finally, there were notable differences between the transfer performance of the visual decorticate rats in Experiment 2 and the transfer performance of the normal animals in Experiment 1. For example, when the brain-injured rats transferred to the $\mathrm{Hr}$ component cues after learning the $\mathrm{B} / \mathrm{Hr}$ compound or transferred to the B-component cues after learning the $\mathrm{B} / \mathrm{Hi}$ compound, their performance was not different from that of similarly treated normal animals $[\mathrm{t}(16)=.571$ and $\mathrm{t}(15)=1.873$, respectively; $\mathrm{ps}$ $=$ n.s.]. However, the lesioned rats performed significantly worse than the normal rats in transferring to the B-component cues after learning the $\mathrm{B} / \mathrm{Hr}$ compound $[t(16)=4.108, p<.001]$. Again, these empirical results were directly in accord with the predictions of compensation theory.

All in all, we interpret the behavior of the visual decorticate rats in Experiment 2 as being due to but a single one of the many consequences of neocortical brain injury. Namely, when given the opportunity to do so, visual decorticate rats will underutilize the lesioned visual system and will respond on the basis of neural systems less directly affected by the brain insult. Compensation thus appears to be a dominant influence when visual decorticate rats attempt new learning. Our final question, then, was whether this compensatory consequence of brain injury also would hold when the rat attempted to recover a preoperatively established behavior that, while disrupted by visual decortication, could nonetheless be demonstrated to have been spared (Davis \& LeVere, 1979; LeVere \& Davis, 1977; LeVere et al., 1979; LeVere \& Morlock, 1973, 1974).

\section{EXPERIMENT 3}

The compensation theory of a postoperative behavioral deficit explains the deficit by suggesting that the brain-injured subject responds to the injury by preferentially utilizing those neural systems not directly affected by the lesion. The result of this shift in behavioral control is that the lesioned neural system does not influence overt behavior and any behavior that is dependent upon this neural system is not expressed independently of what may have been spared. Or, stated otherwise, the theory suggests that compensation is the antithesis of the successful recovery of any spared behavior controlled by the neural system sustaining the insult. It is this prediction that Experiment 3 tests.

The procedure to accomplish this test was first to train normal rats only with brightness cues and then to subject them to posterior visual decortication. During postoperative training, however, the brightness cues were compounded with haptic cues to determine the occurrence of lesion-induced compensatory responding. If compensatory responding were to occur, our predictions would be quite straightforward. First, if the haptic components of the brightness/haptic compounds were redundant to the brightness cues and thus relevant to the discrimination task, then the rats should have performed well but recovered little of the originally learned brightness discrimination. This was so because the animals' compensatory responding, that is, their responding to the haptic cues, would have been successful and the animal would not have utilized whatever was spared of the lesioned visual system. On the other hand, if the haptic component was random with respect to the brightness cues and thus irrelevant to the discrimination task, then the rats should have ultimately recovered the brightness habit but should have been severely impaired in this effort. In other words, the theory predicts that compensation conflicts with the successful expression of spared behavioral capacities controlled principally by the neural system sustaining the insult.

\section{Method}

Subjects. The subjects for this experiment were 29 male hooded rats between the ages of 90 and 120 days. The animals were from our colony and were maintained as described in Experiments 1 and 2.

Apparatus. The apparatus, visual cues, and haptic cues were identical to those used in Experiments 1 and 2.

Procedure. The experiment was an exact replication of Experiment 2, with the sole exception that all animals were trained to criterion on a discrimination task involving only the brightnesscomponent cues before undergoing visual decortication.

Surgery and Histology. Surgery and histology were as described for Experiment 2.

\section{Results and Discussion}

Histology. Figure 2 shows the surface diagrams of the brains of the animals sustaining the smallest and largest lesions. The mean cortical destruction found in the animals of the $\mathrm{B} / \mathrm{Hr}$ group that transferred to the brightness component was $42.8 \%$, and the mean destruction of the animals that transferred to the haptic component was $41.7 \%$. The mean cortical destruction of the animals in the $\mathrm{B} / \mathrm{Hi}$ group was $43.3 \%$. These differences were not significant $(\mathrm{F}<1)$.

Microscopic analysis of the cresyl-stained material produced results identical to those described in Experiment 2.

Behavior. The results of this experiment are presented in Table 3, which duplicates Table 2 and adds the recovery data of Experiment 3. There were 14.0 preoperative mean errors to criterion for the postoperatively trained $\mathrm{B} / \mathrm{Hr}$ animals and 13.5 preoperative mean errors to criterion for the postoperatively 

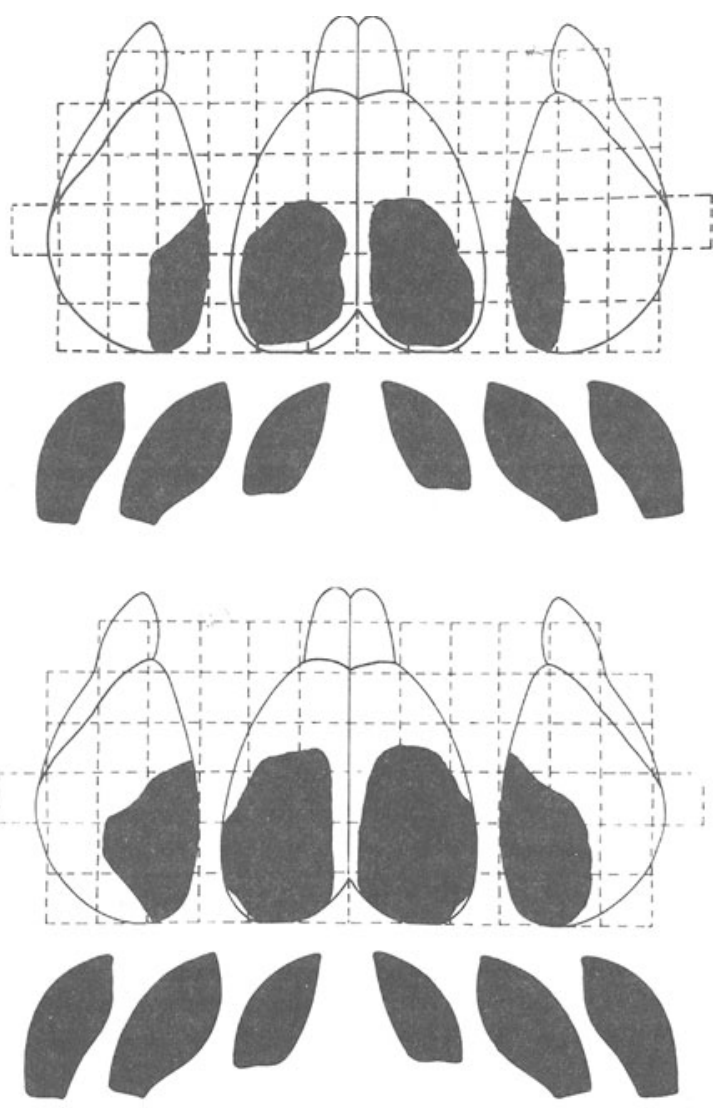

Figure 2. Diagrams of the animals sustaining the smallest and largest lesions in Experiment 3. The figure is organized as Figure 2 is.

trained $\mathrm{B} / \mathrm{Hi}$ animals. These preoperative originallearning error scores were not significantly different $[\mathrm{t}(27)=.194, \mathrm{p}=\mathrm{n} . \mathrm{s}$.), so the preoperative data were pooled for analysis $(B=13.8)$. With the $B / H r$ compound cues, there were 8.0 postoperative recovery mean errors to criterion for the animals that transferred to the B-component cues and $\mathbf{8 . 5}$ for the animals that transferred to the Hr-component cues. This difference was also not significant $[t(17)=.146]$, so the postoperative $\mathrm{B} / \mathrm{Hr}$ data were pooled for analysis.

Consider first the recovery performance of the lesioned animals trained with the $\mathrm{B} / \mathrm{Hr}$ compound cues and the lesioned animals trained with the $\mathrm{B} / \mathrm{Hi}$ compound cues. During this initial postoperative training, the animals were significantly impaired by the presence of irrelevant haptic cues $[t(27)=7.029$, $p<.001]$. This was, of course, predictable not only from compensation theory, but also from the performance of the normal animals (Experiment 1) and lesioned animals (Experiment 2) that originally learned to discriminate these types of compound cues. However, what is of major interest here is that the recovery performance of the $\mathrm{B} / \mathrm{Hr}$-trained ani- mals was significantly better than original preoperative learning with just the $B$ cues $[t(46)=2.786$, $\mathrm{p}<.011$. It appears as though the compound-cue training actually facilitated recovery of function, a tempting but, unfortunately, incorrect conclusion when one considers how these $\mathrm{B} / \mathrm{Hr}$ animals performed during their transfer training.

The transfer-training mean error scores are given in the last column of Table 3, which shows that the superior postoperative recovery performance of the $\mathrm{B} / \mathrm{Hr}$ animals was not because recovery of function per se was facilitated. Rather, it seems that these rats performed superiorly because they were compensating and responding to the $\mathrm{Hr}$ component of the compound $\mathrm{B} / \mathrm{Hr}$ cues, just as the lesion-first rats of Experiment 2 did. For example, the $\mathrm{B} / \mathrm{Hr}$ animals in Experiment 3 that transferred to the $\mathrm{Hr}$-component cues reattained criterion performance after committing a mean of only 3.1 errors, which was significantly better than the scores for both the original preoperative learning with just the B-component cues $[\mathrm{t}(37)=4.877, \mathrm{p}<.001]$ and the initial postoperative training with the $\mathrm{B} / \mathrm{Hr}$ compound cues $[\mathrm{t}(27)=2.077$, $\mathrm{p}<.05$ ]. However, the $\mathrm{B} / \mathrm{Hr}$ rats in Experiment 3 that transferred to the B-component cues committed an average of 9.6 errors in reattaining criterion performance. This was not significantly different from the original preoperative learning with the same brightness cues $[\mathrm{t}(36)=1.784]$ or from the initial postoperative training on the $\mathrm{B} / \mathrm{Hr}$ problem $[\mathrm{t}(26)=$ $.474]$. In other words, the recovery animals of Exper-

Table 3

\begin{tabular}{|c|c|c|c|c|c|}
\hline \multicolumn{6}{|c|}{ Training } \\
\hline \multicolumn{2}{|c|}{ Preop } & \multicolumn{2}{|c|}{ Compound Cue } & \multicolumn{2}{|c|}{ Transfer } \\
\hline Cue & Errors & Cue & Errors & Cue & Errors \\
\hline \multicolumn{6}{|c|}{ Normal Group } \\
\hline \multirow{2}{*}{ NA } & \multirow{2}{*}{ NA } & $\mathrm{B} / \mathrm{Hr}$ & 7.6 & $\mathrm{~B}$ & 2.0 \\
\hline & & $\mathrm{B} / \mathrm{Hi}$ & 16.0 & B & $\begin{array}{l}1.0 \\
1.6\end{array}$ \\
\hline \multicolumn{6}{|c|}{ Lesion-First Group } \\
\hline \multirow{2}{*}{ NA } & \multirow{2}{*}{ NA } & $\mathrm{B} / \mathrm{Hr}$ & 3.8 & \multirow{2}{*}{$\begin{array}{l}\text { B } \\
\mathrm{Hr} \\
\mathrm{B}\end{array}$} & \multirow{2}{*}{$\begin{array}{l}9.9 \\
1.1 \\
3.9\end{array}$} \\
\hline & & $\mathrm{B} / \mathrm{Hi}$ & 28.1 & & \\
\hline \multicolumn{6}{|c|}{ Recovery Group } \\
\hline \multirow{2}{*}{$\mathrm{B}$} & \multirow{2}{*}{13.8} & \multirow{2}{*}{$\mathrm{B} / \mathrm{Hr}$} & 8.3 & B & 9.6 \\
\hline & & & 33.1 & $\begin{array}{l}\mathrm{Hr} \\
\mathrm{B}\end{array}$ & $\begin{array}{l}3.1 \\
3.9\end{array}$ \\
\hline
\end{tabular}

Note $-B=$ brightness cues (always relevant, dark correct); $\mathrm{Hr}=$ haptic cues when relevant (and redundant to brightness cues in compound cues); $\mathrm{Hi}=$ haptic cues when irrelevant (and random to brightness cues in compound cues); $\mathrm{B} / \mathrm{Hr}=$ compound cues composed of brightness components and relevant haptic components; $\mathrm{B} / \mathrm{Hi}=$ compound cues composed of brightness components and irrelevant haptic components; $N A=$ not applicable. Animals in the recovery groups sustained visual decortication between preop and compound-cue training. 
iment 3 performed better during their initial postoperative training with the $\mathrm{B} / \mathrm{Hr}$ compound cues, not because their recovery of function was facilitated visà-vis the preoperative brightness habit, but because they were compensating for the visual decortication and responding to the $\mathrm{Hr}$-component cue.

However, if this is true, then it is necessary to explain why the recovery rats performed significantly worse than the lesion-first rats of Experiment 2 when trained on the same $\mathrm{B} / \mathrm{Hr}$ problem $[\mathrm{t}(37)=2.592$, $\mathrm{p}<.02]$. That is, if the recovery animals in Experiment 3 were just like the lesion-first animals of Experiment 2 and were compensating for the striate ablation by responding to the $\mathrm{Hr}$-component cues, then why did they not do as well? It is important, however, to remember that the recovery rats of Experiment 3 were not just like the lesion-first rats, because they had preoperatively learned a brightness discrimination, which is spared by visual decortication (see summaries by LeVere, 1975, 1980). What we are suggesting is that, in the present case, the spared memories of the preoperatively learned brightness habit interfered with postoperative compensation in such a way that the recovery animals could not be as successful with the $\mathrm{B} / \mathrm{Hr}$ problem as the lesion-first animals, which had no such memories. Thus, it appears that not only does Experiment 3 support the compensation theory, but that it also demonstrates again that, although the preoperative behaviors associated with a lesioned neural system may be disrupted, they may, nonetheless, be spared by the brain injury and may have a significant influence on postoperative behavior.

The remainder of the Table 3 recovery data are virtually identical to those found with the lesion-first animals and are interpreted similarly as support for the compensation theory of the postoperative behavioral deficit.

\section{DISCUSSION}

Recently it has been theorized that many of the behavioral dysfunctions that follow brain injury may be caused by a failure of the individual to utilize the injured neural system. It has been suggested further that this underutilization results from the individual's attempts to circumvent the effects of the injury by shifting behavioral control to other neural systems not directly affected by the injury. Thus, certain behaviors may not be expressed; that is, there is a behavioral deficit, not because of some loss of neural capacity, but rather because the capacity is suppressed by compensation. The present research was a test of this compensation theory of the behavioral deficit and involved providing visual decorticate rats both visual and nonvisual cues during postoperative recovery training. Our prediction was that, if the compensation theory was valid, then the visual decorticate rat would initially behave on the basis of the nonvisual cues and that this would effectively eliminate or severely retard recovery of visual functions.

The results were in direct accord with this prediction and provided what was rather convincing evidence for the compensation theory. For example, the visual decorticate rat recovered little of a preoperatively acquired brightness habit if it was allowed the opportunity to behave on the basis of relevant nonvisual cues. On the other hand if these same nonvisual cues were available but irrelevant, then postoperative recovery of the brightness discrimination occurred but was drastically retarded. Moreover, and perhaps more important, this compensation occurred independently of any specific preoperative behavior. We suggest that this was so because compensation is a general response to brain injury and is not dependent on whether the subject is recovering some particular preoperatively acquired behavior.

These results are also in agreement with a number of other investigations that indicate that the braininjured subject preferentially utilizes those neural systems not affected by the neural insult. Some of these were noted in the introduction to the present research. An additional example is the data reported by Nonneman and Warren (1977). Although this research was not directly concerned with recovery of function, it is nonetheless a particularly clear example of the persistent occurrence of compensation induced by brain injury. The investigation used cats, which normally respond to auditory cues in preference to other sensory cues. However, Nonneman and Warren equated the saliency of an auditory and a visual cue so that both normal cats and cats with auditory neocortex lesions would respond equally well to either cue when it alone indicated the spatial location of food reward. Following this, Nonneman and Warren tested how the normal and lesioned cats responded when both cues were presented simultaneously and the animals were forced to choose between them. In this case, the normal cats responded to the location of the auditory cue, as was expected of normal cats. On the other hand, the auditory lesioned cats responded to the location of the visual cue even though these same cats were proficient with the auditory cue when it was presented alone. We suggest that the reason for this is that, when allowed the opportunity to do so, the lesioned subject attempts to compensate for its brain injury by relying on those neural systems not directly affected by the lesion. The present experiment extends this finding and demonstrates that this type of lesioninduced compensatory response tendency can not only influence long-term postoperative performance, but can also severely mitigate the initial process of recovery of function. Moreover, and most important, the results reported by Nonneman and Warren 
and the results of the present experiment adequately demonstrate that the overt behavior of the braininjured subject is by no means exclusively a function of lost behavioral and neural capacities. Rather, it is apparent in both sets of data that the critical question centers on the rules that determine whether what is spared is expressed.

This, then, brings the discussion to perhaps the most important aspect of the present research, the fact that, while the experiments were designed to test one particular theory of the effects on brain injury, they also addressed an accepted belief that has burdened much of our effort to understand recovery of function. The belief is that neurological losses yield commensurate behavior losses. This is, of course, the cornerstone of the concept of localization of function and provides a major justification for investigating brain-behavior relationships by assessing the effects of localized neural injury (see Glassman, 1978, and Woolsey, 1978). Unfortunately, although both the concept of localization and the lesion method have contributed much to our appreciation of brain function, they have at the same time emphasized the problematic goal of recovery of function as the determination of the mechanisms whereby these behavioral losses might be reversed.

This emphasis, however, may be quite incorrect, since when recovery of function occurs, it is often the case that what first appears to be a behavioral loss is not really a loss at all. For example, the rat's "loss" of a preoperatively learned brightness habit following visual decortication (Lashley, 1935) now can be shown, with appropriate tests, to be spared (Braun et al., 1967; LeVere \& Morlock, 1973). The point is that there may be many reasons why a braininjured subject is unable to perform some particular behavior after brain injury, and an induced behavioral loss is but one of these reasons. Notwithstanding these and similar demonstrations of sparing (see LeVere, 1975, 1980), recovery of function research has concentrated almost exclusively on what the brain-injured subject cannot do as the result of neurological losses and how these losses are subsequently reversed by subtle physiological responses to the injury. It is our position, however, that we must know not only what the brain-injured subject cannot do, but also, and more important for recovery of function, what exactly the brain-injured subject does do. The general theoretical message of the present research is that one of the more critical things that the brain-injured subject does do is to attempt to compensate for the brain injury. And we suggest that it is this compensation that can generate rather severe interference which must be dealt with before it is possible to anticipate even some minimal measure of recovery of function.

\section{REFERENCES}

Braun, J. J., Meyer, P. M., \& Meyer, D. R. Sparing of a brightness habit in rats following visual decortication. Journal of Comparative and Physiological Psychology, 1966, 61, 79-82.

Cooper, R. M., Bland, B. H., Gillespie, L. A., \& Whitaker, R. H. Unilateral posterior cortical and unilateral collicular lesions and visually guided behavior in the rat. Journal of Comparative and Physiological Psychology, 1970, 72, 286-295.

DAvis, N., \& LEVERE, T. E. Recovery of function after brain damage: Different processes and the facilitation of one. Physiological Psychology, 1979, 7, 233-240.

Glassman, R. B. The logic of the lesion experiment and its role in the neural sciences. In S. Finger (Ed.), Recovery from brain damage. New York: Plenum Press, 1978.

Glendenning, R. L., Howard, R. L., \& MeYer, D. R. Stimulus displays which yield rapid learning of two-choice discrimination problems by rats. Behavior Research Methods and Instrumentation, 1971, 3, 313-315.

Goldberger, M. E. Restitution of function in the CNS: The pathologic grasp reflex. Experimental Brain Research, 1972, 15, 79-96.

Guth, L. Axonal regeneration and functional plasticity in the central nervous system. Experimental Neurology, 1974, 45, 606-654.

Hughes, H. C. Anatomical and neurobehavioral investigations concerning the thalamo-cortical organization of the rat's visual system. Journal of Comparative Neurology, 1977, 175, 311-335.

Kirvel, R. D., Greenfield, R. A., \& Meyer, D. R. Multimodal sensory neglect in rats with radical unilateral posterior ablations. Journal of Comparative and Physiological Psychology, 1974, 87, 156-162.

LASHLEY, K. S. Studies of cerebral function in learning: V. The retention of motor habits after destruction of the so-called motor areas in primates. Archives of Neurology and Psychiatry, 1924, 12, 249-276.

LASHLEY, K. S. The mechanism of vision: XII. Nervous structures concerned in habits based on reactions to light. Comparative Psychology Monographs, 1935, 11, 43-79.

LAurence, S., \& STEin, D. G. Recovery after brain damage and the concept of localization of function. In S. Finger (Ed.), Recovery from brain damage. New York: Plenum Press, 1978.

LEVERE, T. E. Neural stability, sparing, and behavioral recovery following brain damage. Psychological Review, 1975, 82, 344-358.

LEVERE, T. E. Recovery of function after brain damage: A theory of the behavioral deficit. Physiological Psychology, $1980,8,297-308$.

LEVERE, T. E., \& Davis, N. Recovery of function after brain damage: The motivational specificity of spared neural traces. Experimental Neurology, 1977, 57, 883-899.

LeVere, T. E., Davis, N., \& Gonder, L. Recovery of function after brain damage: Toward understanding the deficit. Physiological Psychology, 1979, 7, 317-326.

LeVere, T. E., \& Morlock, G. W. The nature of visual recovery following posterior decortication in the hooded rat. Journal of Comparative and Physiological Psychology, 1973, 83, 62-67.

LEVERE, T. E., \& Morlock, G. W. The influence of preoperative learning on the recovery of a successive brightness discrimination following posterior neodecortication in the hooded rat. Bulletin of the Psychonomic Society, 1974, 4, 507-509.

Meyer, D. R. Access to engrams. American Psychologist, 1972, 27, 124-133.

Meyer, P. M., Horel, J. A., \& Meyer, D. R. Effects of dlamphetamine upon placing responses in neodecorticate cats. Journal of Comparative and Physiological Psychology, 1963, 56, 402-404. 
Nonneman, A. J., \& Warren, J. M. Two-cue learning by braindamaged cats. Physiological Psychology, 1977, 5, 397-402.

Sperry, R. W. Effect of crossing nerves to antagonistic limb muscles in the monkey. Archives of Neurology and Psychiatry, $1947,58,452-473$.

SPRAGUe, J. M. Interaction of cortex and superior colliculus in mediation of visually guided behavior in the cat. Science, 1966, 153, 1544-1547.
Woolsey, T. A. Lesion experiments: Some anatomical considerations. In S. Finger (Ed.), Recovery from brain damage. New York: Plenum Press, 1978.

(Manuscript received August 11, 1981;

revision accepted for publication February 15, 1982.)

\section{ERRATUM}

Physiological Psychology, Vol. 10 (1), March 1982. The year shown on the spine of this issue is incorrect. Instead of March 1981, it should have been March 1982. The error is regretted. To avoid confusion, subscribers should correct 1981 to read 1982. 